\title{
Anterior Single Odontoid Screw Fixation for Type II Odontoid Fractures: In A Cohort Study of 11 Patients and Literature Review
}

\author{
Hüseyin Bozkurt ${ }^{1}$, Densel Araç² \\ ${ }^{1}$ Cumhuriyet University, Faculty of Medicine, Department of Neurosurgery, Sivas, Turkey \\ ${ }^{2}$ Necmettin Erbakan University Meram Faculty of Medicine,Department of Neurosurgery, Konya, Turkey \\ Received: 06 September 2019, Accepted: 02 April 2020, Published online: 30 April 2020 \\ (C) Ordu University Institute of Health Sciences, Turkey, 2020
}

\begin{abstract}
Objective: We aim to demonstrate the fusion efficiency of anterior screw fixation technique in all types of type 2 odontoid fracture by presenting a study of 11 cases and updating the literature.

Methods: Retrospectively we analyzed 11 ( 8 males and 3 females) patients with type 2 odontoid fracture treated through anterior odontoid screw fixation in the Neurosurgery Department of XXX University Hospital between 2015 and 2018. All patient records were evaluated with current clinical, neurophysiological examination, radiological studies, and results. In operation we used retropharyngeal approach of Robinson and Smith and created a gutter in the superior edge of $\mathrm{C} 3$ corpus for proper trajection of screw. The patients were followed over a minimum period of eighteen months with a range (18-24 months). Assessments of the union, nonunion, screw displacement and overall, with complications were all recorded.

Results: 10 patients had no postoperative complication. Separation of odontoid fracture was observed in 1 patient after discharge from hospital, but during follow up period computerized tomography revealed fusion of the odontoid of the patient. Our patients had no complication such as screw related problems, pseudoarthrosis and dysphagia.

Conclusion: We recommend surgical treatment in all cases of type 2 odontoid fractures, including the anterior oblique fracture. The method used in our study is more reliable for trajection of screw and suitable for type 2 odontoid fracture, also fusion rate is higher than the other techniques
\end{abstract}

Key words: Odontoid, fractures, Screw fixation

Suggested Citation: Bozkurt H, Arac D. Anterior Single Odontoid Screw Fixation for Type II Odontoid Fractures: In A Cohort Study of 11 Patients and Literature Review. Middle Black Sea Journal of Health Science, 2010; 6(1):1-5.

\section{Address for correspondence/reprints:}

Hüseyin Bozkurt

Telephone number: +90 (533) 4513964

ORCID-ID 0000-0001-64325371

E-mail: bozkurthuseyinn@gmail.com

DOI: $10.19127 / \mathrm{mbsjohs.} 616788$

\section{Introduction}

Fracture of the odontoid process of the axis is a common type of all cervical spine injuries. The fracture occurs at the junction of the odontoid and vertebral body of the axis (Anderson and D'Alanzo., 1974). Anderson and D'Alonzo classified the odontoid fractures into 3 groups according to their types the most frequently observed type is type II fractures and they are thought to be unstable (Keskin et al., 2014).

Conservative treatment methods using for type 1 and 3 odontoid fractures includes halo vests (Ryan et al., 1982; Lind et al.,1988). and cervical orthoses 
(Wang et al.,1984). In unstable fractures these methods are poorly tolerated in the elderly and polytrauma patients (Chi et al.,2007).

There are many surgical techniques for the treatment of $\mathrm{C} 2$ fractures including anterior odontoid screw fixation (AOSF) (Apfelbaum et al., 2000; Platzer et al., 2007), posterior stabilization techniques, such as the methods described by Brooks and Jenkins (Brooks et al., 1978), Gallie (1939) and Sonntag et al (1996), and posterior trans articular screw fixation of C1-C2 (Koller et al., 2006). However, posterior fusion of $\mathrm{C} 1-\mathrm{C} 2$ is associated with considerable mortality and morbidity and results in a decrease in the range of movement of the neck (Fielding at all., 1976; Koller H et al., 2006). Direct anterior screw fixation provides immediate spinal stabilization, preserves rotation of $\mathrm{C} 1$ on $\mathrm{C} 2$, and allows rapid return to normal lifestyle (Hanssen et al., 1987). Therefore, anterior odontoid screw fixation is considered ideal technique for unstable odontoid fractures. This method was performed first by Bohler (Hanssen et al., 1987) in year 1982 and it's become increasingly popular day by day.

We treated eleven cases with unstable odontoid type II fractures with anterior odontoid screw fixation technique in our institution and good functional results were achieved. In this paper we discuss the clinical, radiological and physical applications of the patients treated with anterior single odontoid screw fixation.

\section{Methods}

We reviewed eleven patients with acute type II odontoid fractures managed with anterior single odontoid screw fixation between 2015-2018. This study was approved by the local ethical committee with the number 2018-01/07. Written consent for the management was obtained from all the patients.

All patients records were reviewed for clinical presentation, neurological examination, imaging studies and outcomes. There were 8 males and 3 females. Their mean age at presentation was 64,54 (with a range 28-89). All cases were Type II odontoid fracture, classified by the Anderson and D'Alonzo system. 7 cases of them had fracture line from anterior to postero-superior and 4 cases of them had fracture line from posterior to anterior. There were no other spinal column injuries identified in the patients. The patients had no additional traumatic abdominal, thoracal or orthopedic pathology. The patients were first evaluated with X-ray examination, thereafter computerized tomography (CT) and magnetic resonance imaging (MRI) of the spine were evaluated.CT is the most effective and rapid diagnostic method for detecting traumatic brain and cervical injury with head trauma(Y1lmaz et al., 2019). CT was performed to diagnose the type and pattern of the $\mathrm{C} 2$ vertebra fracture and to rule out other accompanied bony injuries. MRI was performed to determine the integrity of the transvers ligament, other soft tissue injuries and cord injuries. Instability and the direction of displacement were determined using the method described by Roy-Camille et al (Mestdagh et al., 2014).

The patients were operated with anterior odontoid single screw technique and followed over a minimum period of eighteen months with a range (18-24 months). Assessments of the union, nonunion, screw displacement and overall, with complications were all recorded. Cervical tomography was performed to the patients on 1st day for the location and trajectory of screw and in the next 1,3 and 6 months for the fusion of odontoid.

\section{Operative Technique}

We used the retropharyngeal approach of Robinson and Smith (Robinson RA et al., 2014). During surgery, the patient was placed in the supine position under general anesthesia. With a right transverse skin incision at the level of the C5-6 disc space, performed an anteromedial approach. Blunt dissection was used to arrive at the anterior border of the spinal column and to expose the antero-inferior margin of $\mathrm{C} 2$. For image control with $\mathrm{C}$-arm, a puncture needle was inserted into the $\mathrm{C} 2-3$ disc space. After the image control we curetted so as to make a gutter on the superior aspect of the $\mathrm{C} 3$ body (Figüre 1). This is very helpful for accurate placement of the odontoid screw.

The correct angle of the screw is about in line with the cervical spine and therefore sufficiently definition of the sternum is necessary. For correct positioning of the patient to ensure the trajectory of the screw in the midline, we assured that the tip of the nose, suprasternal notch and the sternum were in the same line.

The C-arm images in the antero-posterior and lateral view usually ensure the correct location of the dens. The sharp tipped $1.2 \mathrm{~mm} \mathrm{~K}$-wire was inserted through the guide into the odontoid distal fragment with a power-drill. To achieve compression the thread of the screw must also extend through the posterior apical cortex of the dens (Figüre 1). 


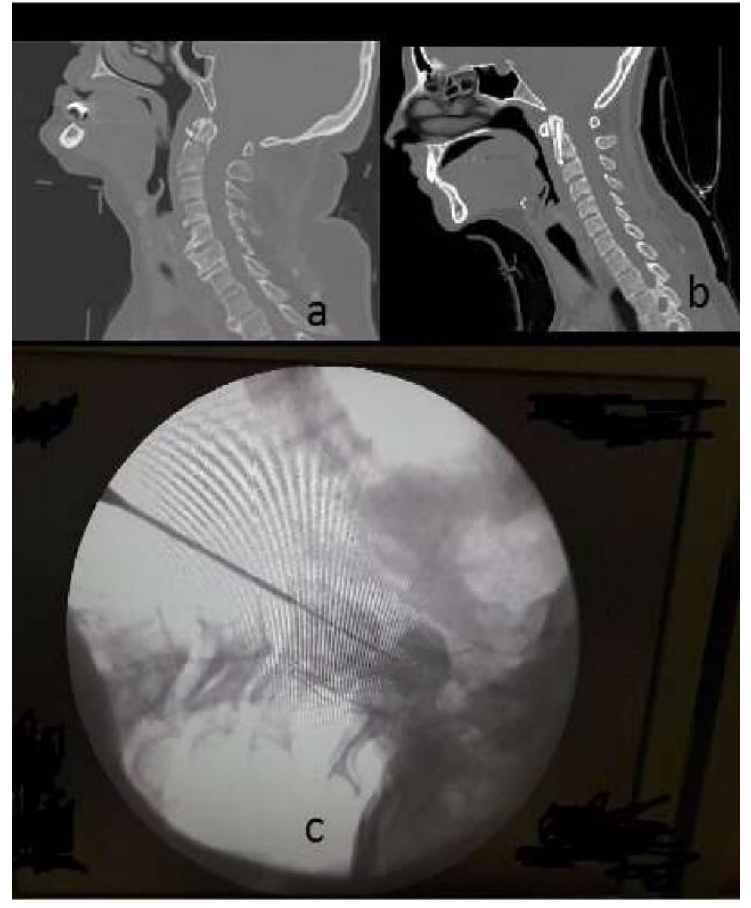

Figüre 1: Pre-op type 2 odontoid fracture (a) and post-op CT image are seen (b). During surgery trajection of guide is seen; placed in a gutter on C3 antero-superior part and oriented towards to fractured dens apex (c).

\section{Results}

In our cohort study, there was a male preponderance (male: female ratio of 8:3). Age of the patients ranged from 28 to 89 years and mean age was 64.54. The causes of injury, 5 of the patients had fall from height $(45,45 \%), 3$ of them were motor vehicle accident $(27,27 \%)$ and 3 of them fell down stairs $(27,27 \%)$. All of the patients were in Frankel grade E status at presentation $(100 \%)$.

In our cohort study, 10 cases had nopostoperative complication. One case was discharged in the early postoperative period with a suitable cervical tomography images. At the month control, CT scan revealed separation of $\mathrm{C} 2$ along the screw line on the sagittal axis. Because of fusion of $\mathrm{C} 2$ during followup period of this patient we did not think to revision. There were no instances of wrong trajectory or false location of the screw head in our study. During the follow up visits, we found good union of all the fractures without any reports of screw malfunctioning. None of our cases had to be reoperated because of screw related problems or pseudo-arthrosis. The most frequent postoperative complaint was dysphagia in anterior odontoid fixation surgery, while no complication was observed in any of our patients.

\section{Discussion}

The technique of minimally invasive spinal surgery has developed rapidly in the recent decades. Percutaneous anterior odontoid screw fixation was reported in a cadaveric study (Kazan et al., 1999). Clinical research and minimally invasive surgical results have shown that blood loss is low. Rapid recovery was observed in those who applied C5based midline incision from the medial border of the sternocleidomastoid muscle. Dissection then proceeds in a similar fashion as compared to the anterior cervical disectomy procedure (Matz et al., 2009).

We preferred this technique because of better surgical exposure, avoiding injury to adjacent structure and screw was sent to tip of the odontoid with a better and easier angle. We created a small gutter on the superior aspect of C3 body like as Sunil Munakomi et al technique, by this method we ensure accurate placement of the odontoid screw behind the anterior cortex of $\mathrm{C} 2$ body without deviation from midline. The groove also provides the proper shelter for the screw head avoiding damage to the eosephagus (Munakomi et al., 2016).

Apfelbaum in a follow-up of 129 patients with recent odontoid fracture, found significantly higher nonunion rates in case of anterior oblique fracture compared to the other forms (Apfelbaum et al., 2000). Likewise, Dantas et al. (2002) reported 94\% union in posterior oblique and horizontal fracture and advised against anterior screwing in anterior oblique fractures. In contrast to these studies, nonunion complication was not seen in our three cases $(27,27 \%)$ because of direct observation of dens and $\mathrm{C} 2$ corpus during procedure and we could manipulate the neck of the patients.

Pepin et al (1985) made special reference to 19 odontoid fractures in patients older than 60 years. In their series, three (16\%) who died were all older than 78 years and had been treated with a halo device. They found this treatment to be poorly tolerated in the elderly and recommended early surgical treatment. 2 of our patients $(18.18 \%)$ were more than 80 years old and had multisystemic pathologies but no mortality. We can depend this situation to the short duration of our surgery.

Major limitations of the procedure are the need for intact integrity of the transverse ligament and the prerequisite of attaining normal alignment of the spine before screw placement (Munakomi et al., 2016). Therefore, preoperative cervical MRI was 
seen in all our cases and the integrity of the transverse ligament was confirmed.

Through this method, the rate of fusion increases to as high as $80-100 \%$ (Aebi et al., 1989; Dickman et al., 1995). Compared to the posterior approach, the most important advantages of this method are the protection of the atlantoaxial joint movements, no need for a bone graft, better postoperative comfort of the patients, and shorter length of stay in the hospital (Hadley et al., 2002). In all of our cases we only used one screw but still attained satisfactory union of the fracture. Anterior odontoid screw methodcan causecomplication such as vascular injury, spinal cord injury and disphagia related to implant malpositioning and nonunion. We did not have such complications in our cohort study.

\section{Conclusion}

Anterior odontoid screw method has not yet been accepted as a single treatment modality for odontoid fracture. Anterior screwing is a successful technique in case of horizontal or posterior oblique fractures, conserving $\mathrm{C} 1-\mathrm{C} 2$ joint mobility in literature.

Our experience with the management of odontoid fractures with the anterior placement of screw for the fixation of fractured bones supports the use of this techniques as a satisfactory measure. We recommend surgical treatment independently of the age and type of fracture in all casesof type 2 odontoid fractures, including the anterior oblique fracture. The method used in our study is more reliable for trajection of screw and suitible for type 2 odontoid fracture, also fusion rate is higher than the other techniques.

Ethics Committee Approval: Ethics committee approval was received for this study from local ethical committee with the number 2018-01/07, Clinical Research Ethics Committee of Cumhuriyet University.

Peer-review: Externally peer-reviewed.

Author Contributions: Concept - H.B; Design H.B; Supervision D.A; Materials- H.B, D.A; Data Collection and/or Processing- H.B, D.A; Analysis and/or Interpretation- H.B, D.A; Literature ReviewAK, HGU; Writing- HB; Critical Review- HB.

Conflict of Interest: No conflict of interest was declared by the authors.

Financial Disclosure: The authors declared that this study hasn't received no financial support.

\section{References}

Aebi M, Etter C, Coscia M: Fractures of the odontoid process. Treatment with anterior screw fixation. Spine 1989; 14(10): 1065-1070.

Anderson LD, D'Alonzo RT: Fractures of the odontoid process of the Axis. J Bone and Joint Surg, 1974; 56(8): 1663-1674.

Apfelbaum RI, Lonser RR, Veres R, Casey A. Direct anterior screw fixation for recent and remote odontoid fractures. Journal of Neurosurgery: Spine. 2000; 93(2):227-36

Brooks AL, Jenkins EB. Atlanto-axial arthrodesis by the wedge compression method. J Bone Joint Surg Am. 1978; 60(3):279-84.

Chi YL, Wang XY, Xu HZ, Lin Y, Huang QS, Mao FM, et al. Management of odontoid fractures with percutaneous anterior odontoid screw fixation. Eur Spine J 2007;16:1157-64.

Dantas FL, Prandini MN, Caires AC, Fonseca GA, Raso JL. Management of odontoid fractures using anterior screw fixation: analysis of 15 cases. Arq Neuropsiquiatr 2002;60:823-29.

Dickman CA, Foley KT, Sonntag VK, Smith MM: Cannulated screws for odontoid screw fixation and atlantoaxial transarticular screw fixation. Technical note. J Neurosurg 1995; 83(6):10951100.

Keskin F, Gomleksız C, SasanI M, Oktenoglu T, Suzer T, Ozer AF. Clinical Results of Anterior Odontoid Screw Fixation for Type II Odontoid Fractures. Turk Neurosurg 2014; 24( 5):750-756.

Fielding JW, Hawkins RJ, Ratzan SA. Spine fusion for atlanto-axial instability. J Bone Joint Surg [Am] 1976;58-A:400-407.

Gallie WE. Fractures and dislocations of the cervical spine. Am J Surg. 1939; 46(3):495-9.

Hadley MN, Walters BC, Grabb PA, Oyesiku NM, Przybylski GJ, Resnick DK, Ryken TC: 1solated fractures of the axis in adults. Neurosurgery 2002; 50 (3): 125-139

Hanssen AD, Cabanela ME. Fractures of the dens in adult patients. J Trauma. 1987;27:928-34.

Kazan S, Tuncer R, Sindel M. Percutaneous anterior odontoid screw fixation technique. A new instrument and a cadaveric study. Acta Neurochir (Wien) 1999;141:521-24.

Koller H, Kammermeier V, Ulbricht D, Assuncao A, Karolus S, van den Berg B, et al. Anterior retropharyngeal fixation C1-2 for stabilization of atlantoaxial instabilities: study of feasibility, technical description and preliminary results. Europ Spine J. 2006; 15(9):1326-38. 
Lind B, Sihlbom H, Nordwall A. Halo vest treatment of unstable traumatic cervical spine injuries. Spine 1988; 13:425-32.

Matz PG, Ryken TC, Groff MW, et al.: Techniques for anterior cervical decompression for radiculopathy. J Neurosurg Spine. 2009; 11(2): 183-197.

Mestdagh H, Vigier P, Berger M, Urvoy P. Results of atlantoaxial arthrodesis with posterior cerclage for fractures of the odontoid process: propos of 59 cases. Ann Chir 1988;42:492-500.

Munakomi S, Tamrakar K, Chaudhary PK and Bhattarai B. Anterior single odontoid screw placement for type II odontoid fractures: our modified surgical technique and initial results in a cohort study of 15 patients 2016;5:1681.

Pepin JW, Bourne RB, Hawkins RJ. Odontoid fracture, with special reference to the elderly patient. Clin Orthop 1985;193:178-83.

Platzer P, Thalhammer G, Ostermann R, Wieland T, Vécsei V, Gaebler C. Anterior screw fixation of odontoid fractures comparing younger and elderly patients. Spine. 2007; 32(16):1714-20.

Ryan MD, Taylor TKF. Odontoid fractures: a rational approach to treatment. J Bone Joint Surg [Br] 1982;64-B:416-21.

Robinson RA, Smith GW. Anterolateral cervical disc removal and interbody fusion for cervical disc syndrome. Bull John Hopkins Hosp 1955;96:22324.

Sonntag VK, H Dickman CA, Vardiman A. Anterior odontoid screw fixation. Principles of spinal surgery. New York: McGraw-Hill; 1996. 103949.

Yilmaz A, Altas H. Incidental Findings on Cranial CT Scans of Children With Head Trauma .Annals of Medical Research 2019;26(6):1060-64.

Wang G-J, Mabie KN, Whitehill R, Stamp WG. The nonsurgical management of odontoid fractures in adults. Spine 1984;9:229-30. 